\title{
Prevalence of Severe Obesity among Primary School Children in 21 European Countries
}

\author{
Angela Spinellia Marta Buoncristiano ${ }^{b} \quad$ Viktoria Anna Kovacs $^{c}$ \\ Agneta Yngve $^{d}$ Igor Spiroski ${ }^{e}$ Galina Obreja ${ }^{f}$ Gregor Starc $^{g}$ \\ Napoleón Pérez ${ }^{\text {h }}$ Ana Isabel Ritoi Marie Kunešováj \\ Victoria Farrugia Sant'Angelok Jørgen Meisfjord' Ingunn Holden Bergh ${ }^{m}$ \\ Cecily Kelleher $^{n} \quad$ Nazan Yardim $^{\circ}$ Iveta Pudule $^{p} \quad$ Ausra Petrauskiene $^{q}$ \\ Vesselka Dulevar $^{r}$ Agneta Sjöberg $^{s}$ Andrea Gualtieri ${ }^{t}$ \\ Maria Hassapidou ${ }^{u}$ Jolanda Hyskav Genc Burazeriv \\ Constanta Huidumac Petrescuw ${ }^{\text {w }}$ Mirjam Heinen ${ }^{\text {n }}$ Hajnalka Takacs ${ }^{x}$ \\ Hana Zamrazilováj Tulay Bagci Bosi ${ }^{y} \quad$ Elena Sacchini ${ }^{z}$ loannis Pagkalos ${ }^{u}$ \\ Alexandra Cucuw ${ }^{w}$ Paola Nardone ${ }^{a}$ Paul Gately ${ }^{A}$ Julianne Williams ${ }^{b}$ \\ João Bredab
}

${ }^{a}$ Istituto Superiore di Sanità (National Institute of Health), National Centre for Disease Prevention and Health Promotion, Rome, Italy; ${ }^{b}$ WHO European Office for the Prevention and Control of the NCDs, Moscow, Russian Federation; ${ }^{c}$ National Institute of Pharmacy and Nutrition, DG of Food and Nutrition Science, Budapest, Hungary; ${ }^{d}$ Department of food studies, Nutrition and Dietetics, Uppsala University, Uppsala, Sweden; ${ }^{\mathrm{e}}$ Institute of Public Health of the Republic of Macedonia, Skopje, Republic of Macedonia; 'State University of Medicine and Pharmacy, Chișinău, Moldova; ${ }^{9}$ Faculty of Sport, University of Ljubljana,

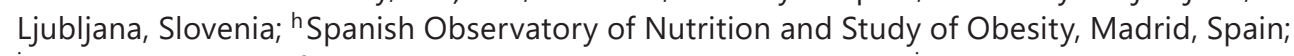
iNational Institute of Health Dr. Ricardo Jorge, Lisbon, Portugal; ' 'Obesity Management Centre, Institute of Endocrinology, Prague, Czech Republic; ${ }^{\mathrm{k} P r i m a r y}$ Health Care, Floriana, Malta; 'Department of Health and Inequality, Division of Mental and Physical Health, Norwegian Institute of Public Health, Oslo, Norway; ${ }^{m}$ Department of Child Health and Development, Division of Mental and Physical Health, Norwegian Institute of Public Health,

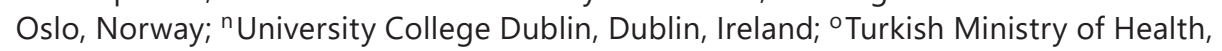
Ankara, Turkey; ${ }^{\mathrm{P}}$ Centre for Disease Prevention and Control, Riga, Latvia; ${ }^{9}$ Department of Preventive Medicine, Lithuanian University of Health Sciences, Kaunas, Lithuania; 'National Center of Public Health and Analyses, Sofia, Bulgaria; ${ }^{5}$ Department of Food and Nutrition

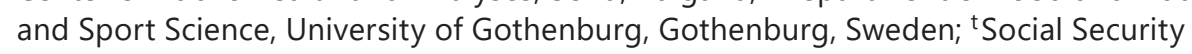

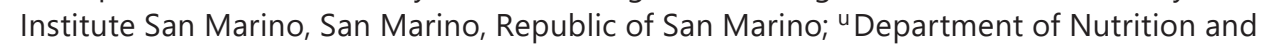
Dietetics, Alexander Technological Educational Institute of Thessaloniki, Thessaloniki, Greece; vInstitute of Public Health, Tirana, Albania; "National Institute of Public Health, Bucharest, Romania; ' Semmelweis University, Karoly Racz School of PhD Studies, Budapest, Hungary; ${ }^{y}$ Public Health Department, Hacettepe University, Ankara, Turkey; ${ }^{\mathrm{z} H e a l t h}$ Authority San Marino, San Marino, Republic of San Marino; ${ }^{A}$ Centre for Applied Obesity Research, Leeds Beckett University, Leeds, UK 
Spinelli et al.: Childhood Severe Obesity in Europe

\title{
Keywords
}

Obesity · BMI · Childhood Obesity Surveillance Initiative $\cdot$ Europe

\begin{abstract}
Background: The World Health Organization (WHO) European Childhood Obesity Surveillance Initiative (COSI) was established more than 10 years ago to estimate prevalence and monitor changes in overweight and obesity in children aged 6-9 years. Since then, there have been five rounds of data collection in more than 40 countries involving more than half a million children. To date, no comparative studies with data on severe childhood obesity from European countries have been published. Objectives: The aim of this work was to present the prevalence of severe obesity in school-aged children from 21 countries participating in COSI. Method: The data are from cross-sectional studies in 21 European WHO member states that took part in the first three COSI rounds of data collection (2007/2008, 2009/2010, 2012/2013). School-aged children were measured using standardized instruments and methodology. Children were classified as severely obese using the definitions provided by WHO and the International Obesity Task Force (IOTF). Analyses overtime, by child's age and mother's educational level, were performed in a select group of countries. Results: A total of 636,933 children were included in the analysis (323,648 boys and 313,285 girls). The prevalence of severe obesity varied greatly among countries, with higher values in Southern Europe. According to the WHO definition, severe obesity ranged from $1.0 \%$ in Swedish and Moldovan children $(95 \% \mathrm{Cl}$ $0.7-1.3$ and $0.7-1.5$, respectively) to $5.5 \%(95 \% \mathrm{Cl} 4.9-6.1)$ in Maltese children. The prevalence was generally higher among boys compared to girls. The IOTF cut-offs lead to lower estimates, but confirm the differences among countries, and were more similar for both boys and girls. In many countries 1 in 4 obese children were severely obese. Applying the estimates of prevalence based on the WHO definition to the whole population of children aged 6-9 years in each country, around 398,000 children would be expected to be severely obese in the $21 \mathrm{Eu}$ ropean countries. The trend between 2007 and 2013 and the analysis by child's age did not show a clear pattern. Severe obesity was more common among children whose mother's educational level was lower. Conclusions: Severe obesity is a serious public health issue which affects a large number of children in Europe. Because of the impact on educational, health, social care, and economic systems, obesity needs to be addressed via a range of approaches from early prevention of overweight and obesity to treatment of those who need it.
\end{abstract}

(C) 2019 The Author(s)

Published by S. Karger AG, Basel

\section{Introduction}

Childhood obesity is one of the major public health concerns of the 21st century. A pooled analysis of 2,416 population-based measurement studies showed that from 1975 to 2016 there was a rising trend in children's and adolescents' BMI [1]. In 2016, 124 million children and adolescents, aged 5-19 years, were estimated to suffer from obesity worldwide, and 213 million were overweight [1].

Childhood obesity is associated with immediate adverse consequences, such as psychological problems and lower educational attainment, and a higher risk for many harmful comorbidities later in life, such as type 2 diabetes mellitus, dyslipidemia, non-alcoholic fatty liver disease, hypertension, and coronary heart disease [2-5]. In most cases, obesity is the result of chronic caloric imbalance, with more calories being consumed than expended each day. Hereditary, environmental, metabolic, behavioural, mental, cultural, and socioeconomic factors (along with having a history of obesity) all play a role in the development of obesity. In children, the relation between body mass index (BMI) and adiposity varies with age and 
Spinelli et al.: Childhood Severe Obesity in Europe

sex, so BMI thresholds are usually defined in terms of specific centiles on a growth reference curve [6]. Extremely high BMI values considerably increase children's physical and mental health risks [7-11]. When compared with children with overweight or obesity, who often do not experience visible morbidities during childhood, children with severe obesity frequently have immediate health consequences, including a worse cardiometabolic risk profile, earlier signs of vascular dysfunction, and subclinical atherosclerosis [12-23]. They are also more likely to suffer from depression $[9,11]$ due to teasing and bullying, as well as other social risks. Persistence of adiposity from childhood to adulthood is much more common for severely obese children $[24,25]$. There is a lack of a standard definition of severe obesity in children, both in terminology (severe obesity can be a synonym for morbid or extreme obesity) and in the methodology that defines it, which makes interpreting data about its prevalence difficult [26]. In 2007, the Centers for Disease Control and Prevention (CDC) proposed the age and gender-specific 99th percentile and above of their growth curves as a definition of severe obesity in children [27], while the World Health Organization (WHO) growth reference curves from 2007 enable the extrapolation of a cut-off to define severe obesity [28] at $+3 Z$-scores relative to the median. In 2012, the International Obesity Task Force (IOTF) also provided extended cut-offs including the cut-offs for morbid (severe) obesity [29].

While there are a good number of studies about the prevalence of severe obesity in American children [30-37], the evidence on severe childhood obesity prevalence in Europe is scarce [26, 38-41]. Moreover, no publication comparing data from different European countries has been found.

The aim of this paper is therefore to assess the prevalence of severe obesity in 6- to 9-year-old school children from 21 countries of the WHO European Region, which participated in the WHO European Childhood Obesity Surveillance Initiative (COSI) data collections between 2007 and 2013.

\section{Materials and Methods}

The first data collection in primary school children according to the COSI surveillance methodology took place in 2007/2008, the second in 2009/2010, and the third in 2012/2013. The number of countries that collected data has increased over time from 12 in the first round to 14 in the second round, and 19 in the third (Table 1). Overall, 21 countries have participated in at least 1 round of data collection within the period 2007-2013: 10 countries took part in all rounds, ${ }^{1} 4$ in 2 rounds, ${ }^{2}$ and 7 in just 1 round, ${ }^{3}$ most of them in the third round. Data collection followed a common protocol that was developed in 2007 by the WHO Regional Office for Europe together with the member states, and slightly amended for COSI rounds 2 and 3 [42-45].

According to the COSI protocol, countries could choose one or more of the following age groups: 6.0-6.9, 7.0-7.9, 8.0-8.9, or 9.0-9.9 years. Belgium and Slovenia included all age groups (only in 2009/10 and 2012/13). Among the other countries, most considered 7-year-old children (Bulgaria, Czech Republic, Greece, Hungary, Ireland, Lithuania, Latvia, Malta - only in 2012/2013; Moldova, Portugal, Spain, Sweden, Republic of Macedonia - only in 2009/2010, and Turkey). Spain and Sweden also targeted 8-year-old children, and Greece

1 Belgium, Czech Republic, Ireland, Italy, Latvia, Lithuania, Malta, Norway, Portugal, and Slovenia.

2 Bulgaria - 2007/08 and 2012/13, Greece - 2009/10 and 2012/13, Spain - 2009/10 and 2012/13, Republic of Macedonia - 2009/10 and 2012/13.

3 Albania - 2012/13, Hungary - 2009/10, Republic of Moldova - 2012/13, Romania - 2012/13, San Marino - 2012/13, Turkey - 2012/13, and Sweden - 2007/08. 
Table 1. Targeted age groups and availability of the family forms in COSI round $1(2007 / 2008)$, round $2(2009 / 2010)$, and round 3 (2012/2013), by country

\begin{tabular}{|c|c|c|c|c|c|c|}
\hline \multirow[t]{2}{*}{ Country } & \multicolumn{2}{|l|}{ Round 1} & \multicolumn{2}{|l|}{ Round 2} & \multicolumn{2}{|l|}{ Round 3} \\
\hline & $\begin{array}{l}\text { age group, } \\
\text { years }\end{array}$ & $\begin{array}{l}\text { family } \\
\text { form }\end{array}$ & $\begin{array}{l}\text { age group, } \\
\text { years }\end{array}$ & $\begin{array}{l}\text { family } \\
\text { form }\end{array}$ & $\begin{array}{l}\text { age group, } \\
\text { years }\end{array}$ & $\begin{array}{l}\text { family } \\
\text { form }\end{array}$ \\
\hline Albania & NP & & NP & & 8 & \\
\hline Belgium & $6,7,8,9$ & & $6,7,8,9$ & & $6,7,8,9$ & \\
\hline Bulgaria & 7 & $\checkmark$ & NP & & 7 & $\checkmark$ \\
\hline Czech Republic & 7 & $\checkmark$ & 7 & $\checkmark$ & 7 & $\checkmark$ \\
\hline Greece & NP & & 7,9 & & 7,9 & \\
\hline Hungary & NP & & 7 & & NP & \\
\hline Ireland & 7 & & 7 & $\checkmark$ & 7 & $\checkmark$ \\
\hline Italy & 8,9 & & 8,9 & $\checkmark$ & 8,9 & $\checkmark$ \\
\hline Latvia & 7 & & 7 & & 7 & \\
\hline Lithuania & 7 & $\checkmark$ & 7 & $\checkmark$ & 7 & $\checkmark$ \\
\hline Malta & 6 & & 6 & & 7 & $\checkmark$ \\
\hline Moldova & NP & & NP & & 7 & $\checkmark$ \\
\hline Republic of Macedonia & NP & & 7 & & 6 & \\
\hline Norway & 8 & & 8 & & 8 & \\
\hline Portugal & 7 & $\checkmark$ & 7 & $\checkmark$ & 7 & $\checkmark$ \\
\hline Romania & NP & & NP & & 8 & \\
\hline San Marino & NP & & NP & & 8,9 & $\checkmark$ \\
\hline Spain & NP & & 7,8 & & 7,8 & $\checkmark$ \\
\hline Slovenia & $6,7,8$ & & $6,7,8$ & & $6,7,8$ & \\
\hline Sweden & 7,8 & $\checkmark$ & NP & & NP & \\
\hline Turkey & NP & & NP & & 7,8 & $\checkmark$ \\
\hline
\end{tabular}

NP, not participant.

9-year-olds. Albania, Norway, and Romania considered only 8-year-old children, and Italy and San Marino 8- and 9-year-olds.

Most countries adopted a two-stage sampling design with primary schools as the primary sampling units (PSU) and whole classes as the secondary sampling units, except in the Czech Republic, Italy, Norway, and Spain, where the PSUs were paediatric clinics, classes, counties, and provinces, respectively. ${ }^{4}$

Three countries included all classes of their targeted grades of primary schools (Belgium, Malta, and San Marino), while a nationally representative sample was selected in the other countries. Among the 12 countries that participated in more than 1 round of data collection, 6 had a sentinel site approach (i.e., involved the same schools that were selected in previous rounds) while 6 countries selected a new sample of schools. ${ }^{5}$ Table 1 reports detailed information for each country.

According to the COSI protocol, the minimum final effective sample size should be 2,800 children per single age group [43]. In 6 countries, the number of children measured was considerably lower $[42,45]$.

4 The sampling process including sample size considerations have been described elsewhere [43, 44].

5 Sentinel site approach: Bulgaria, Ireland, Lithuania, Norway, Portugal, and Republic of Macedonia. New sample of schools: Latvia, Greece, Spain, and Slovenia. New sample of classes: Italy. New sample of paediatric clinics: Czech Republic. 
Spinelli et al.: Childhood Severe Obesity in Europe

During the data collection, children were measured by examiners who were trained in measuring weight and height using the WHO standardized techniques. Measurements were taken after having removed shoes and socks, as well as all heavy clothes (coats, sweaters, jackets, etc.) and items such as wallets, mobile phones, or key chains. Each child was weighed to the nearest $0.1 \mathrm{~kg}$ and height was measured to the nearest $1 \mathrm{~mm}$. Each country provided the average weights of the types of clothes worn during the measurements, which were used to adjust the observed weight.

Besides the record form for registering the child's demographic characteristics and anthropometric measures, COSI also used an optional family record form which was completed by the child's parent or guardian to gather information on the child's eating habits and physical activity patterns. Through the family record form, data on family socioeconomic characteristics, such as parents' education and employment status, were also collected. Given the voluntary nature of the form, not all countries adopted it (Table 1). Twelve of the 21 countries had family data available for at least one COSI round (Bulgaria, Czech Republic, Ireland, Italy, Lithuania, Malta, Moldova, Portugal, San Marino, Spain, Sweden, and Turkey).

The COSI study follows the International Ethical Guidelines for Biomedical Research Involving Human Subjects [46]. Local ethical committees also approved the study. More details on data collection procedures are provided elsewhere [42, 45, 47, 48].

All country datasets were reviewed for inconsistencies and completeness in a standard manner at the WHO Regional Office before they were aggregated for the inter-country comparisons. The final dataset, with data from the all rounds and countries, only included children with informed consent and complete information on age, gender, weight, and height. Children whose age did not fall within the target age group were excluded. Children with biologically implausible (or extreme) values were also excluded from the analysis (i.e., BMIfor-age values below $-5 Z$-scores or above $+5 Z$-scores), as recommended by the WHO [49].

The 2007 WHO cut-offs for school-aged children and adolescents were used to compute anthropometric indicators (height-for-age, weight-for-age, BMI-for-age) and their Z-scores $[28,49]$. Severe obesity was defined as the proportion of children with BMI-for-age above +3 $Z$-scores relative to the 2007 WHO growth reference median. Severe obesity was also estimated using IOTF cut-off points, as they are also widely used in the WHO European Region. According to the IOTF, these points are age (in months) and gender specific, and correspond to a BMI greater than 35 at the age of 18 years [29]. The definition of severe obesity proposed by CDC in 2007 was not applied because percentiles greater than the 97 th are beyond the range of the data used to estimate the growth curves and should be treated with caution [50].

Estimates of the prevalence of severe obesity are presented as percentages and have been calculated by country and gender. In order to protect confidentiality and to improve statistical power, prevalence estimates by round of data collection and target age group have been calculated only for those countries with enough observations and for those who used the same target age group(s) over time. More specifically, changes over time were investigated in 9 countries (Belgium, Bulgaria, Greece, Italy, Latvia, Lithuania, Portugal, Spain, and Slovenia) and age groups were compared for 5 countries (Belgium, Greece, Italy, Slovenia, and Spain).

Sampling weights to adjust for the sampling design, oversampling, and non-response were available only for a few countries. For this reason, the analysis was performed unweighted. Where appropriate, the standard errors and 95\% confidence intervals (CIs) have been estimated taking account of the cluster design using primary sampling units (schools in most countries) and by applying the finite population correction factor. For each country, the estimates of prevalence of severe obesity were adjusted for deviations from the distribution of the target population by gender, age group, and year of data collection according to the most recent data from official statistics [51]. 
Spinelli et al.: Childhood Severe Obesity in Europe

Table 2. Prevalence of severe obesity in boys and girls aged 6-9 years in COSI round 1 (2007/2008), COSI round 2 (2009/2010), and COSI round 3 (2012/2013) by country using the WHO and IOTF definitions - rounds combined

\begin{tabular}{|c|c|c|c|c|c|c|c|}
\hline \multirow[t]{2}{*}{ Country } & \multirow{2}{*}{$\begin{array}{l}\text { Children included } \\
\text { in the } \\
\text { analysis, } n\end{array}$} & \multicolumn{3}{|c|}{$\begin{array}{l}\text { Prevalence of severe obesity - WHO definition, \% } \\
(95 \% \mathrm{CI})\end{array}$} & \multicolumn{3}{|c|}{$\begin{array}{l}\text { Prevalence of severe obesity - IOTF definition, \% } \\
(95 \% \mathrm{CI})\end{array}$} \\
\hline & & Boys & Girls & Total & Boys & Girls & Total \\
\hline Albania $^{1}$ & 3,312 & $2.1(1.4-2.9)$ & $0.4(0.2-0.8)$ & $1.2(0.9-1.7)$ & $0.7(0.4-1.4)$ & $0.4(0.2-0.9)$ & $0.6(0.3-0.9)$ \\
\hline Belgium $^{1}$ & 397,209 & $2.3(2.2-2.4)$ & $1.1(1.1-1.2)$ & $1.7(1.7-1.8)$ & $1.1(1.0-1.1)$ & $1.4(1.3-1.6)$ & $1.2(1.2-1.3)$ \\
\hline Bulgaria $^{1}$ & 5,848 & $5.2(4.4-6.1)$ & $2.8(2.1-3.5)$ & $4.0(3.5-4.6)$ & $2.6(2.0-3.3)$ & $3.3(2.6-4.0)$ & $2.9(2.5-3.4)$ \\
\hline $\begin{array}{l}\text { Czech } \\
\text { Republic }^{2}\end{array}$ & 3,634 & $3.0(2.3-3.9)$ & $1.4(0.9-2.1)$ & $2.2(1.8-2.8)$ & $1.6(1.0-2.2)$ & $1.6(1.0-2.4)$ & $1.6(1.2-2.1)$ \\
\hline Greece $^{1}$ & 10,616 & $7.2(6.2-8.5)$ & $2.4(1.6-3.3)$ & $4.8(4.1-5.7)$ & $2.8(2.2-3.6)$ & $2.7(2.0-3.7)$ & $2.8(2.2-3.4)$ \\
\hline Hungary $^{2}$ & 1,231 & $4.2(2.8-6.3)$ & $2.1(1.2-3.5)$ & $3.1(2.2-4.4)$ & $1.3(0.6-2.6)$ & $2.9(1.9-4.5)$ & $2.1(1.4-3.0)$ \\
\hline Ireland $^{2}$ & 4,395 & $2.1(1.6-2.9)$ & $1.1(0.7-1.6)$ & $1.6(1.2-2.1)$ & $1.0(0.6-1.6)$ & $1.4(1.0-2.0)$ & $1.2(0.9-1.6)$ \\
\hline Italy $^{1}$ & 95,089 & $6.4(6.1-6.7)$ & $2.0(1.8-2.2)$ & $4.3(4.1-4.5)$ & $2.7(2.5-2.9)$ & $2.3(2.1-2.5)$ & $2.5(2.3-2.6)$ \\
\hline Lithuania $^{1}$ & 9,324 & $3.2(2.7-3.7)$ & $1.2(0.9-1.6)$ & $2.2(1.9-2.5)$ & $1.4(1.1-1.7)$ & $1.6(1.3-2.0)$ & $1.5(1.3-1.8)$ \\
\hline Latvia $^{1}$ & 9,561 & $2.7(2.2-3.2)$ & $1.1(0.8-1.5)$ & $1.9(1.6-2.2)$ & $1.2(0.9-1.5)$ & $1.2(1.0-1.6)$ & $1.2(1.0-1.5)$ \\
\hline Malta $^{1}$ & 6,458 & $6.9(6.0-7.9)$ & $4.1(3.4-4.8)$ & $5.5(4.9-6.1)$ & $3.8(3.2-4.5)$ & $4.7(3.9-5.5)$ & $4.2(3.7-4.8)$ \\
\hline Moldova $^{1}$ & 2,573 & $1.4(0.9-2.4)$ & $0.6(0.2-1.3)$ & $1.0(0.7-1.5)$ & $1.0(0.5-1.8)$ & $0.6(0.3-1.3)$ & $0.8(0.5-1.3)$ \\
\hline $\begin{array}{l}\text { Republic of } \\
\text { Macedonia }^{1}\end{array}$ & 4,919 & $6.4(5.4-7.5)$ & $2.3(1.8-3.0)$ & $4.4(3.8-5.1)$ & $3.6(2.9-4.5)$ & $2.9(2.3-3.7)$ & $3.2(2.7-3.8)$ \\
\hline Norway $^{1}$ & 8,328 & $2.1(1.7-2.6)$ & $0.6(0.4-0.9)$ & $1.4(1.1-1.7)$ & $0.9(0.6-1.2)$ & $0.6(0.4-0.9)$ & $0.8(0.6-1.0)$ \\
\hline Portugal $^{1}$ & 6,262 & $4.6(3.9-5.4)$ & $2.2(1.7-2.8)$ & $3.4(3.0-3.9)$ & $2.1(1.6-2.6)$ & $2.9(2.3-3.5)$ & $2.5(2.1-2.9)$ \\
\hline Romania $^{1}$ & 4,274 & $3.8(3.0-4.9)$ & $0.5(0.3-1.0)$ & $2.2(1.8-2.8)$ & $1.7(1.1-2.6)$ & $0.6(0.4-1.1)$ & $1.2(0.9-1.7)$ \\
\hline San Marino & 278 & $5.9(3.0-11.3)$ & $3.1(1.2 .-7.8)$ & $4.6(2.7-7.8)$ & $3.1(1.1-8.0)$ & $3.1(1.2-7.8)$ & $3.1(1.6-6.0)$ \\
\hline Spain $^{1}$ & 7,747 & $5.9(4.6-7.6)$ & $1.9(1.5-2.6)$ & $4.0(3.2-4.8)$ & $2.5(1.8-3.6)$ & $2.3(1.8-3.0)$ & $2.4(2.0-3.1)$ \\
\hline Slovenia $^{1}$ & 47,205 & $4.3(4.0-4.6)$ & $1.7(1.5-1.9)$ & $3.0(2.8-3.2)$ & $1.9(1.7-2.1)$ & $2.1(1.9-2.3)$ & $2.0(1.8-2.1)$ \\
\hline Sweden & 3,716 & $1.2(0.8-1.9)$ & $0.7(0.4-1.2)$ & $1.0(0.7-1.4)$ & $0.5(0.3-1.0)$ & $0.9(0.5-1.5)$ & $0.7(0.4-1.0)$ \\
\hline Turkey $^{1}$ & 4,951 & $3.2(2.7-4.0)$ & $1.2(0.8-1.7)$ & $2.2(1.8-2.7)$ & $1.7(1.2-2.3)$ & $1.3(0.9-1.8)$ & $1.5(1.1-1.9)$ \\
\hline
\end{tabular}

${ }^{1}$ Statistically significant difference between boys and girls in the prevalence of severe obesity (based on WHO definition) - Pearson's $\chi^{2}$ corrected using the Rao-Scott method $<0.001$.

${ }^{2}$ Statistically significant difference between boys and girls in the prevalence of severe obesity (based on WHO definition) - Pearson's $\chi^{2}$ corrected using the Rao-Scott method $<0.05$

Estimates for each country with their $95 \%$ CIs were calculated. The $\chi^{2}$ test was applied for comparison between boys and girls within each country. Binary logistic regression was used to appraise the relation between the probability of being severely obese and the year of measurement and the age group. For each country included in the analysis, a country-specific model with child's gender, age group, and year of data collection as covariates was estimated. Finally, differences by mother's level of education (low-medium level - primary or secondary school; high level - undergraduate/bachelor's degree or master's degree or higher) within the same country were assessed and assumed significant based on a $\chi^{2}$ test. Because of the above-mentioned limit of small numbers, the analysis was run only for 8 out of 12 countries that collected data through the family record form. A $p$ value $<0.05$ was used to define statistical significance. The data were analysed using STATA version 15.1 (Stata Corporation LP, College Station, TX, USA).

\section{Results}

The total number of children aged 6-9 years included in the analysis was 636,933 $(323,648$ boys and 313,285 girls). The number of children varies among countries as a consequence of the number of data collection rounds each country participated in and the adopted study design and sampling strategy. Belgium had the largest number of children included in 
Spinelli et al.: Childhood Severe Obesity in Europe

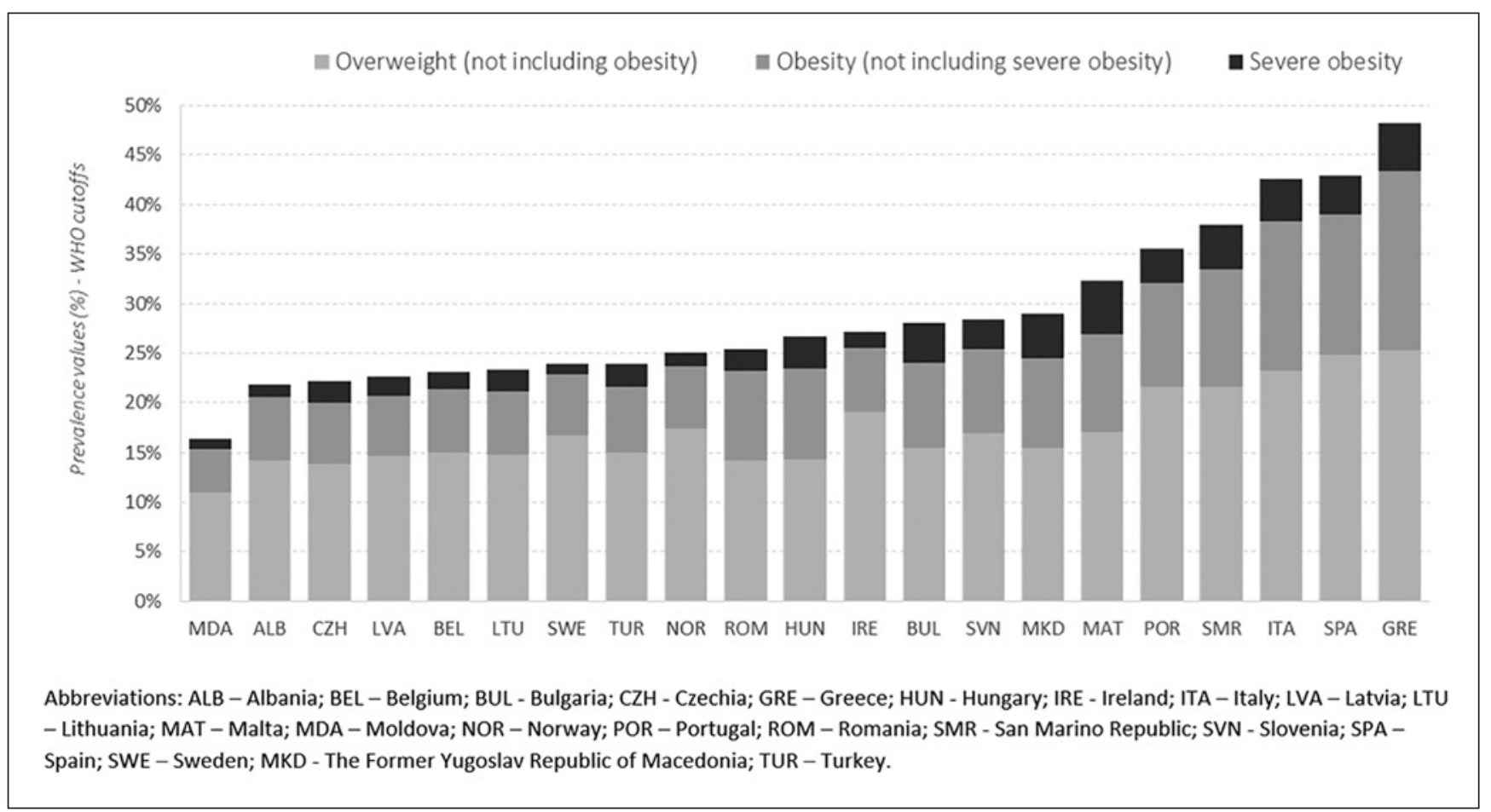

Fig. 1. Prevalence by country of overweight (not including obesity), obesity (not including severe obesity), and severe obesity in children aged 6-9 years (gender and age groups combined) of COSI rounds 1, 2, and 3 (rounds combined) based on WHO definitions.

the analysis (almost 400,000), followed by Italy (almost 100,000) and Slovenia (more than 50,000 ). For other countries, the sample sizes and number of children included were much lower - about 10,000 or fewer (Table 2). More details of study design and sampling strategy are provided elsewhere $[42,45]$. There were great differences in the prevalence of severe obesity between the participating countries. According to the WHO definition, the prevalence of severe obesity ranged from 1.0\% in Swedish and Moldovan children (95\% CI 0.7-1.4 and $0.7-1.5$, respectively) to 5.5\% (95\% CI 4.9-6.1) in Maltese children (Table 2). Countries from Southern Europe (Greece, Malta, Italy, Spain, and San Marino) had the highest levels of severe obesity, above 4\%. In countries from Western and Northern Europe, such as Belgium, Ireland, Norway, and Sweden, the prevalence was below 2\%. A similarly low level was also found in Latvia and Lithuania. In other countries from Central and Eastern Europe (such as Albania, Bulgaria, Czech Republic, Hungary, Moldova, Romania, Slovenia, and Republic of Macedonia), a more heterogeneous picture emerged with prevalence values ranging between 1 and 4\%. While in Bulgaria and the Republic of Macedonia the prevalence of severe obesity was similar to Southern European countries ( 4.0 and 4.4\%, respectively), Moldova and Albania had values among the lowest (1.0 and $1.2 \%$, respectively).

For all countries the IOTF definition yielded lower levels of severe obesity (Table 2) than when using the WHO definition, with IOTF values ranging in prevalence from $0.6 \%(95 \% \mathrm{CI}$ $0.3-0.9$ ) in Albanian children to 4.2\% (95\% CI 3.7-4.8) in Maltese children. Nevertheless, the analysis based on IOTF cut-offs confirms the existence of a great variability among countries, even though the differences were less prominent.

The prevalence based on the WHO definition was much higher in boys than in girls (Table 2). In most countries that showed a statistically significant difference by gender, prevalence 
Spinelli et al.: Childhood Severe Obesity in Europe

Table 3. Multivariate associations between severe obesity based on the WHO definition and COSI rounds of data collection (2007/2008, 2009/2010, 2012/13) in Belgium, Greece, Italy, Lithuania, Latvia, Portugal, Slovenia, and Spain

\begin{tabular}{|c|c|c|c|c|c|c|}
\hline \multirow[t]{2}{*}{ Country } & \multicolumn{3}{|c|}{ Prevalence, \% (95\% CI) } & \multicolumn{3}{|c|}{$\mathrm{OR}_{\mathrm{adj}}(95 \% \mathrm{CI})^{1}$} \\
\hline & $2007 / 08$ & $2009 / 10$ & $2012 / 13$ & $2007 / 08$ & $2009 / 10$ & $2012 / 13$ \\
\hline Belgium & $1.6(1.5-1.7)$ & $1.7(1.6-1.8)$ & $1.8(1.7-1.9)$ & 1 & $1.06(0.97-1.14)$ & $1.11(1.02-1.20)$ \\
\hline Bulgaria & $3.9(3.2-4.8)$ & $\mathrm{NP}$ & $4.1(3.5-4.8)$ & 1 & NP & $1.05(0.80-1.37)$ \\
\hline Greece & NP & $4.9(4.3-5.6)$ & $4.7(3.2-6.9)$ & NP & 1 & $0.97(0.64-1.48)$ \\
\hline Italy & $5.0(4.5-5.6)$ & $4.0(3.7-4.2)$ & $3.9(3.7-4.1)$ & 1 & $0.77(0.68-0.87)$ & $0.75(0.67-0.85)$ \\
\hline Lithuania & $2.1(1.7-2.6)$ & $2.2(1.7-2.7)$ & $2.4(1.9-3.0)$ & 1 & $1.03(0.74-1.43)$ & $1.14(0.82-1.60)$ \\
\hline Latvia & $1.9(1.4-2.4)$ & $2.0(1.6-2.7)$ & $1.8(1.4-2.4)$ & 1 & $1.11(0.76-1.62)$ & $0.98(0.65-1.48)$ \\
\hline Portugal & $4.2(3.3-5.2)$ & $3.1(2.4-4.0)$ & $2.9(2.3-3.6)$ & 1 & $0.74(0.52-1.05)$ & $0.67(0.48-0.94)$ \\
\hline Slovenia & $3.3(3.0-3.7)$ & $3.0(2.8-3.4)$ & $2.7(2.5-2.9)$ & 1 & $0.92(0.79-1.07)$ & $0.80(0.70-0.93)$ \\
\hline Spain & $\mathrm{NP}$ & $3.9(2.6-5.6)$ & $4.0(3.4-4.8)$ & NP & 1 & $1.06(0.66-1.68)$ \\
\hline
\end{tabular}

NP, not participant.

${ }^{1}$ Adjusted ORs were estimated through country-specific logistic models that included child's sex and age in years as covariates.

values in boys were more than twice those among girls. This was not found using the IOTF cut-offs. Differences in the estimated prevalence using WHO and IOTF cut-offs were mainly due to differences observed among boys.

Applying the estimates of prevalence based on the WHO definition to the whole population of children aged 6-9 years in each country, around 398,000 children would be expected to be severely obese in the 21 European countries. The pattern of severe obesity among countries was in line with those of obesity and overweight ${ }^{6}$ - in countries with a higher prevalence of overweight and obesity, severe obesity also tended to be higher (Fig. 1). In many countries 1 in 4 children with obesity were severely obese. The picture was even worse in Bulgaria, Malta, and the Republic of Macedonia, where it was 1 out of 3. On the contrary, in countries affected by lower levels of severe obesity, less than $20 \%$ of the obese children were severely obese.

In Table 3, the prevalence values of severe obesity by COSI round, the odds ratios and 95\% confidence intervals estimated using multivariate logistic regression analysis are reported for the 9 countries where the number of measured children were sufficient for comparisons over time. As already noted, childhood severe obesity varied among these 9 countries. While severe obesity was rare among Belgian, Latvian, and Lithuanian children (below 2\%), Bulgarian, Greek, Italian, and Spanish children were at higher risk of being severely obese ( $4.0 \%$ and above). For Slovenian and Portuguese boys and girls, the risk of severe obesity was between these two $(3.0 \%)$.

The models showed that Italian, Portuguese, and Slovenian children were more likely to be severely obese in $2007 / 2008$ than in the following years of COSI data collection: the adjusted odds ratios were, respectively, 0.77 (95\% CI 0.68-0.87), 0.74 (95\% CI 0.52-1.05), and 0.92 (95\% CI 0.79-1.07) in 2009/2010, and 0.75 (95\% CI 0.67-0.85), 0.67 (95\% CI 0.480.94), and 0.80 (95\% CI $0.70-0.93$ ) in 2012/2013. On the contrary, slightly higher odds of severe obesity have been estimated in the COSI rounds 2 and 3 for Belgium $\left(\mathrm{OR}_{\mathrm{adj}}=1.06 ; 95 \%\right.$ 
Spinelli et al.: Childhood Severe Obesity in Europe

Table 4. Multivariate associations between severe obesity based on the WHO definition and child's age in Belgium, Greece, Italy, Slovenia, and Spain in COSI round 1 (2007/2008), round 2 (2009/2010) and round 3 (2012/2013) - rounds combined

\begin{tabular}{|c|c|c|c|c|c|c|c|c|}
\hline \multirow[t]{2}{*}{ Country } & \multicolumn{4}{|c|}{ Prevalence, \% (95\% CI) } & \multicolumn{4}{|c|}{$\mathrm{OR}_{\mathrm{adj}}(95 \% \mathrm{CI})^{1}$} \\
\hline & 6-year-olds & 7-year-olds & 8-year-olds & 9-year-olds & 6-year-olds & 7-year-olds & 8-year-olds & 9-year-olds \\
\hline Belgium & $1.3(1.3-1.4)$ & $2.4(2.3-2.6)$ & $1.3(1.3-1.4)$ & $1.7(1.6-1.9)$ & 1 & $1.82(1.68-1.97)$ & $0.98(0.92-1.95)$ & $1.31(1.21-1.42)$ \\
\hline Greece & NA & $5.3(4.6-6.1)$ & NA & $4.4(3.3-6.0)$ & NA & 1 & NA & $0.85(0.60-1.19)$ \\
\hline Italy & NA & NA & $4.8(4.6-5.1)$ & $3.7(3.4-4.1)$ & NA & NA & 1 & $0.77(0.70-0.85)$ \\
\hline Slovenia & $2.8(2.5-3.2)$ & $3.0(2.7-3.3)$ & $3.2(2.9-3.5)$ & NA & 1 & $1.07(0.92-1.23)$ & $1.13(0.97-1.31)$ & NA \\
\hline Spain & NA & $4.4(2.9-5.6)$ & $3.9(3.2-4.9)$ & NA & NA & 1 & $0.93(0.74-1.18)$ & NA \\
\hline
\end{tabular}

NA, data not available.

${ }^{1}$ Adjusted ORs were estimated through country-specific logistic models that included child's sex and COSI rounds of data collection as covariates.

Table 5. Prevalence of severe obesity based on the WHO definition by mothers' education level and country in COSI round 1 (2007/2008), round 2 (2009/2010), and round 3 (2012/2013) - rounds combined

\begin{tabular}{|c|c|c|c|c|c|}
\hline \multirow[t]{2}{*}{ Country } & \multirow{2}{*}{$\begin{array}{l}\text { Included } \\
\text { number of } \\
\text { children }\end{array}$} & \multicolumn{2}{|c|}{ Low-medium level of education ${ }^{3}$} & \multicolumn{2}{|c|}{ High level of education ${ }^{3}$} \\
\hline & & $\begin{array}{l}\text { children, } \\
\%\end{array}$ & $\begin{array}{l}\text { prevalence of } \\
\text { severe obesity, \% }\end{array}$ & $\begin{array}{l}\text { children, } \\
\%\end{array}$ & $\begin{array}{l}\text { prevalence of } \\
\text { severe obesity, } \%\end{array}$ \\
\hline Bulgaria & 5,562 & 64.3 & 4.0 & 35.7 & 4.3 \\
\hline Czech Republic ${ }^{2}$ & 6,250 & 69.6 & 3.0 & 30.4 & 0.7 \\
\hline Italy $^{1}$ & 82,691 & 83.5 & 4.2 & 16.5 & 1.9 \\
\hline Lithuania & 7,470 & 57.5 & 2.7 & 42.4 & 2.0 \\
\hline Malta & 1,499 & 64.9 & 6.4 & 35.1 & 4.6 \\
\hline Portugal & 2,964 & 82.6 & 3.8 & 17.4 & 3.2 \\
\hline Spain $^{2}$ & 3,175 & 57.1 & 5.1 & 42.9 & 2.9 \\
\hline Turkey & 4,337 & 89.2 & 2.4 & 10.8 & 2.1 \\
\hline
\end{tabular}

${ }^{1}$ Statistically significant difference of proportions between children with low-medium educated mothers and highly educated mothers for severe obesity (based on the WHO definition) - Pearson's $\chi^{2}$ corrected using the Rao-Scott method $<0.001$.

${ }^{2}$ Statistically significant difference of proportions between children with low-medium educated mothers and highly educated mothers for severe obesity (based on the WHO definition) - Pearson's $\chi^{2}$ corrected using the Rao-Scott method $<0.05$.

${ }^{3}$ Low-medium level of education - primary or secondary school; high level of education - undergraduate/bachelor's degree or master's degree or higher.

CI 0.97-1.14 in 2009/2010, and $\mathrm{OR}_{\mathrm{adj}}=1.11 ; 95 \%$ CI 1.02-1.20 in 2012/2013), even though their values remained low. As for Bulgaria, Greece, Lithuania, Latvia, and Spain, the differences were not statistically significant.

Multivariate regression analysis did not identify an association between age groups and severe obesity among Greek, Slovenian, and Spanish children (Table 4). In Italy, 9-year-old children were at lower risk than 8-year-old children $\left(\mathrm{OR}_{\mathrm{adj}}=0.77 ; 95 \% \mathrm{CI} 0.70-0.84\right)$; while in Belgium children aged 7 and 9 years old were at higher risk compared to children aged 6 years old $\left(\mathrm{OR}_{\mathrm{adj}}=1.81 ; 95 \% \mathrm{CI} 1.72-1.92\right.$, and $\mathrm{OR}_{\mathrm{adj}}=1.31 ; 95 \% \mathrm{CI} 1.24-1.39$, respectively).

Finally, the association between severe obesity and education level of children's mothers was assessed for 8 countries (Table 5). Severe obesity was generally more common among children whose mother's level of education was low or medium compared to those with higher education. 
Spinelli et al.: Childhood Severe Obesity in Europe

\section{Discussion}

Due to the adoption of a common methodology, the direct measurement of children by trained staff and the selection of a nationally representative sample of children, COSI is an important source of data for estimating childhood obesity, comparing the levels among countries, and looking at trends over time. In particular, this study provides the first analysis of the prevalence of severe obesity in measured school-age children living in 21 European countries. The first three rounds of COSI - which took place in $2007 / 2008,2009 / 2010$, and $2012 / 2013$ - showed that the prevalence of childhood severe obesity varied greatly among countries, as has been seen for child hood overweight and obesity [42, 45, 47, 48]. More specifically, there were countries which were less affected by severe obesity (namely Moldova, Albania, and those of Northern Europe), and countries in which it was a more important public health problem (in Southern Europe, Bulgaria, and Republic of Macedonia). Although in the first 3 rounds of data collection of COSI some of the most populous European countries, such as Russia, Germany, France, and the UK, were not included, still almost 400,000 children aged 6-9 years could be expected to be severely obese in the participating 21 European countries in 2013 based on the prevalence calculated using 2007 WHO growth curves. This will doubtlessly impose a great burden on the health care systems of these countries.

The presence of higher prevalence rates of severe obesity in the south is in line with previous studies of obesity and overweight among European children [47, 48, 52], adolescents [53], and adults [54]. The explanation for it remains elusive, but some possible reasons can be suggested. For example, studies of European children and adolescents suggest that the lower height-for-age found in Southern European countries may be one explanation [55]. Other explanations may be linked to birth weight $[56,57]$, sleep duration $[58,59]$, and dietary or physical activity patterns [60]. Relatively low prevalence rates of overweight and obesity were observed in countries that are experiencing a nutrition transition (e.g., Albania and Moldova) [61]. Without timely, appropriate, and effective policy measures to prevent obesity [62], there is a risk that prevalence rates in these countries will eventually match the levels seen in other European countries.

COSI data also indicate that low and medium levels of parental education is a risk factor: in 6 out of 8 countries included in the analysis, children whose mothers had only a primary or secondary school education had a higher prevalence of severe obesity than children whose mothers had a higher education, but only in 3 cases was the difference statistically significant. Although it was not possible to assess properly the impact of family socioeconomic status on severe obesity, differences by mother's education level reinforce that a problem of inequality does exist and that it should be considered when devising strategies to tackle childhood severe obesity. School-based health promotion interventions have the potential to reach children from all socioeconomic backgrounds, and may, therefore, provide an important avenue for addressing health inequalities. Investments must be made to ensure that schools are health-promoting environments. Children also need to be protected from exposure to marketing for foods high in fat, salt, and sugar [62].

COSI was created with the aim of estimating childhood overweight and obesity prevalence across European countries over time through routine nationally representative surveys. The sample size suggested by the protocol [43] was established for producing estimates of overweight and obesity which are much more prevalent than severe obesity. Moreover, 6 countries had a sample size much lower than that suggested (approx. 2,800 measured children per age group). The number of measured children limits the precision of the investigation of childhood severe obesity. The sample size in some countries limited the possibility of producing robust and reliable estimates of the prevalence of childhood severe obesity by 
Spinelli et al.: Childhood Severe Obesity in Europe

round of data collection and age group, especially when using the IOTF definition. Despite these limits, it was possible to assess changes over time for 9 countries, 3 slightly affected by childhood severe obesity (Belgium, Lithuania, and Latvia), and 4 with a high prevalence (Bulgaria, Greece, Italy, and Spain).

COSI data show a decrease of severe childhood obesity over time (starting from $2007 / 2008$ ) in Italy, Portugal, and to a lesser extent in Slovenia, while the other countries do not show any great difference. The association between severe obesity and age is less clear; in Italy severe obesity is less common among children aged 9 compared to those aged 8, while in Belgium the prevalence for children aged 7 and 9 years compared to 6 and 8 years and in Greece, Slovenia, and Spain was not statistically significant.

An important limitation to all studies of severe obesity is that, due to early stigmatization, there might be a higher refusal to participate by the child or the parents if the child is severely obese $[63,64]$, which can produce an underestimate of the problem. The extent of this bias cannot be usefully estimated in a study of this design. Thus, the estimates reported in this study should be regarded as an underestimate of the true extent of the problem.

The application of different definitions of severe obesity leads to different estimates; prevalence values based on WHO cut-offs in all countries were notably higher than those based on IOTF cut-offs. The divergence mainly regarded the estimation of severe obesity prevalence among boys, which tended to be more than double using WHO growth curves compared with IOTF cut-offs. Despite this difference, the study confirms that, in several countries, childhood severe obesity should be tackled as an important health problem.

\section{Conclusion}

Acting on childhood obesity - including severe obesity - can have major benefits for child health and well-being, but also for national health care services and economies. When countries develop processes for monitoring childhood obesity like COSI, it ensures that national obesity strategies - both for prevention and treatment - can be evaluated. COSI also offers the unique possibility of comparing data of several European countries that share the same methodology to assess the weight status of school-aged children. This study is the first that investigates the prevalence of severe obesity in school children with a representative sample from 21 European countries. Severe obesity is a serious public health issue and the results of this study show that a large number of children in Europe suffer from it. Given its impact on education, health, social care, and the economy, obesity needs to be addressed via a range of approaches, from prevention to early diagnosis and treatment $[65,66]$.

\section{Acknowledgements}

The authors gratefully acknowledge Laurence Doughan of the Federal Public Service of Public Health, Food Security Chain and Environment, and Machtel Wauters of Flemish Agency for Care and Health for providing data collected in Belgium. The authors also gratefully acknowledge support from a grant from the Russian Government in the context of the WHO European Office for the Prevention and Control of NCDs. 
Spinelli et al.: Childhood Severe Obesity in Europe

\section{Statement of Ethics}

Children and their parents gave their informed consent. The study protocol was approved by the research institute's committee on human research of the participating countries.

\section{Disclosure Statement}

The writing group takes sole responsibility for the content of this article and the content of this article reflects the views of the authors only. Dr. João Breda and Dr. Julianne Williams are staff members of the WHO and Dr. Marta Buoncristiano is a WHO consultant. The authors alone are responsible for the views expressed in this publication and they do not necessarily represent the decisions or the stated policy of the World Health Organization.

\section{Funding Sources}

Data collection in the countries was made possible through funding by: Albania: Institute of Public Health; Belgium: Flemish Agency for Care and Health and Ministry of Education, Youth, Equal Opportunities and Brussels Affairs; Bulgaria: Ministry of Health, National Center of Public Health and Analyses, World Health Organization Regional Office for Europe; Czech Republic: supported by grants AZV MHCR 17-31670 A and MH CZ-DRO (Institute of Endocrinology - EU, 00023761); Greece: Alexander Technological Educational Institute of Thessaloniki (ATEITH) and Hellenic Medical Society for Obesity (HMSO); Hungary: WHO Country Office for Hungary; Ireland: Health Services Executive; Italy: Ministry of Health and Istituto Superiore di Sanità (National Institute of Health); Latvia: Ministry of Health; Lithuania: Department of Preventive Medicine, Lithuanian University of Health Sciences; Republic of Macedonia: Ministry of Health and Institute of Public Health; Malta: Ministry for Health; Republic of Moldova: World Health Organization; Norway: The Norwegian Directorate of Health and the Norwegian Institute of Public Health; Portugal: Ministry of Health Institutions, the National Institute of Health, Directorate General of Health, Regional Health Directorates and the kind technical support of the Center for Studies and Research on Social Dynamics and Health (CEIDSS); Romania: National Institute of Public Health Bucharest, and World Health Organization Regional Office for Europe; San Marino: The Health Ministry, The Educational Ministry, the Social Security Institute and the Health Authority; Slovenia: Ministry of Education, Science and Sport; Spain: Spanish Ministry of Health; Sweden: The Swedish Research Council for Health, Working Life and Welfare (for the eastern and northern parts of Sweden, the Karolinska Institutet); funding for COSI Sweden 2008: The Swedish Research Council, The Swedish Council for Working Life and Social Research; Turkey: World Bank.

\section{Author Contributions}

A.Sp. conceptualized and drafted the manuscript. M.B. conducted all analyses and made substantial contributions to the drafts of the paper. J.B. made substantial contribution to the conception and drafts of both the manuscript and the COSI study protocol as well as interpretation of the results. J.W. and P.G. were involved in critically reviewing the drafts of the manuscript. V.A.K., A.Y., I.S., G.O., G.S., N.P., A.I.R., M.K., V.F.S., J.M., I.H.B, P.N. commented on the draft of the paper and contributed with data collection and data cleaning. C.K., N.Y., I.Pu., A.P., V.D., A.Sj., A.G., M.Ha., J.H., G.B., C.H.P, M.He., H.T., H.Z., T.B.B., E.S., I.Pa. contributed with data collection and data cleaning. All authors contributed to and approved the report. 
Spinelli et al.: Childhood Severe Obesity in Europe

\section{References}

1 Abarca-Gómez L, Abdeen ZA, Hamid ZA, Abu-Rmeileh NM, Acosta-Cazares B, Acuin C, et al.; NCD Risk Factor Collaboration (NCD-RisC). Worldwide trends in body-mass index, underweight, overweight, and obesity from 1975 to 2016: a pooled analysis of 2416 population-based measurement studies in 128.9 million children, adolescents, and adults. Lancet. 2017 Dec;390(10113):2627-42.

2 Park MH, Falconer C, Viner RM, Kinra S. The impact of childhood obesity on morbidity and mortality in adulthood: a systematic review. Obes Rev. 2012 Nov;13(11):985-1000.

3 World Health Organization. Childhood overweight and obesity [cited 2018 Dec 14]. Available from: http:// www.who.int/dietphysicalactivity/childhood/en/.

4 Rankin J, Matthews L, Cobley S, Han A, Sanders R, Wiltshire HD, et al. Psychological consequences of childhood obesity: psychiatric comorbidity and prevention. Adolesc Health Med Ther. 2016 Nov; 7:125-46.

5 Pulgarón ER. Childhood obesity: a review of increased risk for physical and psychological comorbidities. Clin Ther. 2013 Jan;35(1):A18-32.

6 Rolland-Cachera MF. Childhood obesity: current definitions and recommendations for their use. Int J Pediatr Obes. 2011 Oct; 6(5-6):325-31.

7 Smego A, Woo JG, Klein J, Suh C, Bansal D, Bliss S, et al. High body mass index in infancy may predict severe obesity in early childhood. J Pediatr. 2017 Apr;183:87-93.e1.

8 Franklin J, Denyer G, Steinbeck KS, Caterson ID, Hill AJ. Obesity and risk of low self-esteem: a statewide survey of Australian children. Pediatrics. 2006 Dec;118(6):2481-7.

9 Luppino FS, de Wit LM, Bouvy PF, Stijnen T, Cuijpers P, Penninx BW, et al. Overweight, obesity, and depression: a systematic review and meta-analysis of longitudinal studies. Arch Gen Psychiatry. 2010 Mar;67(3):220-9.

10 Delgado Floody PA, Caamaño-Navarrete F, Martínez-Salazar C, Jerez-Mayorga D, Carter-Thuiller B, García Pinillos F, et al. [Childhood obesity and its association with the feeling of unhappiness and low levels of selfesteem in children of public schools]. Nutr Hosp. 2018 Jun;35(3):533-7. Spanish.

11 Quek YH, Tam WW, Zhang MW, Ho RC. Exploring the association between childhood and adolescent obesity and depression: a meta-analysis. Obes Rev. 2017 Jul;18(7):742-54.

12 Freedman DS, Mei Z, Srinivasan SR, Berenson GS, Dietz WH. Cardiovascular risk factors and excess adiposity among overweight children and adolescents: the Bogalusa Heart Study. J Pediatr. 2007 Jan;150(1):12-17.e2.

13 Calcaterra V, Klersy C, Muratori T, Telli S, Caramagna C, Scaglia F, et al. Prevalence of metabolic syndrome (MS) in children and adolescents with varying degrees of obesity. Clin Endocrinol (Oxf). 2008 Jun;68(6):868-72.

14 Gidding SS, Nehgme R, Heise C, Muscar C, Linton A, Hassink S. Severe obesity associated with cardiovascular deconditioning, high prevalence of cardiovascular risk factors, diabetes mellitus/hyperinsulinemia, and respiratory compromise. J Pediatr. 2004 Jun;144(6):766-9.

15 Ice CL, Murphy E, Cottrell L, Neal WA. Morbidly obese diagnosis as an indicator of cardiovascular disease risk in children: results from the CARDIAC Project. Int J Pediatr Obes. 2011 Apr;6(2):113-9.

16 Kapiotis S, Holzer G, Schaller G, Haumer M, Widhalm H, Weghuber D, et al. A proinflammatory state is detectable in obese children and is accompanied by functional and morphological vascular changes. Arterioscler Thromb Vasc Biol. 2006 Nov;26(11):2541-6.

17 Kelly AS, Hebbel RP, Solovey AN, Schwarzenberg SJ, Metzig AM, Moran A, et al. Circulating activated endothelial cells in pediatric obesity. J Pediatr. 2010 0ct;157(4):547-51.

18 Kelly AS, Metzig AM, Schwarzenberg SJ, Norris AL, Fox CK, Steinberger J. Hyperleptinemia and hypoadiponectinemia in extreme pediatric obesity. Metab Syndr Relat Disord. 2012 Apr;10(2):123-7.

19 Messiah SE, Carrillo-Iregui A, Garibay-Nieto G, Lopez-Mitnik G, Cossio S, Arheart KL. Inter- and intra-ethnic group comparison of metabolic syndrome components among morbidly obese adolescents. J Clin Hypertens (Greenwich). 2010 Aug;12(8):645-52.

20 Norris AL, Steinberger J, Steffen LM, Metzig AM, Schwarzenberg SJ, Kelly AS. Circulating oxidized LDL and inflammation in extreme pediatric obesity. Obesity (Silver Spring). 2011 Jul;19(7):1415-9.

21 Schlager 0, Willfort-Ehringer A, Hammer A, Steiner S, Fritsch M, Giurgea A, et al. Microvascular function is impaired in children with morbid obesity. Vasc Med. 2011 Apr;16(2):97-102.

22 Tounian P, Aggoun Y, Dubern B, Varille V, Guy-Grand B, Sidi D, et al. Presence of increased stiffness of the common carotid artery and endothelial dysfunction in severely obese children: a prospective study. Lancet. 2001 Oct;358(9291):1400-4.

23 Weiss R, Dziura J, Burgert TS, Tamborlane WV, Taksali SE, Yeckel CW, et al. Obesity and the metabolic syndrome in children and adolescents. N Engl J Med. 2004 Jun;350(23):2362-74.

24 Simmonds M, Llewellyn A, Owen CG, Woolacott N. Predicting adult obesity from childhood obesity: a systematic review and meta-analysis. Obes Rev. 2016 Feb;17(2):95-107.

25 Puhl RM, King KM. Weight discrimination and bullying. Best Pract Res Clin Endocrinol Metab. 2013 Apr;27(2): 117-27.

26 Lombardo FL, Spinelli A, Lazzeri G, Lamberti A, Mazzarella G, Nardone P, et al.; OKkio alla SALUTE Group 2010. Severe obesity prevalence in 8- to 9-year-old Italian children: a large population-based study. Eur J Clin Nutr. 2015 May;69(5):603-8.

27 Barlow SE; Expert Committee. Expert committee recommendations regarding the prevention, assessment, and treatment of child and adolescent overweight and obesity: summary report. Pediatrics. 2007 Dec;120 Suppl 4:S164-92. 
Spinelli et al.: Childhood Severe Obesity in Europe

28 de Onis M, Onyango AW, Borghi E, Siyam A, Nishida C, Siekmann J. Development of a WHO growth reference for school-aged children and adolescents. Bull World Health Organ. 2007 Sep;85(9):660-7.

29 Cole TJ, Lobstein T. Extended international (IOTF) body mass index cut-offs for thinness, overweight and obesity. Pediatr Obes. 2012 Aug; 7(4):284-94.

30 Skinner AC, Perrin EM, Moss LA, Skelton JA. Cardiometabolic Risks and Severity of Obesity in Children and Young Adults. N Engl J Med. 2015 Oct;373(14):1307-17.

31 Skinner AC, Skelton JA. Prevalence and trends in obesity and severe obesity among children in the United States, 1999-2012. JAMA Pediatr. 2014 Jun;168(6):561-6.

32 Skelton JA, Cook SR, Auinger P, Klein JD, Barlow SE. Prevalence and trends of severe obesity among US children and adolescents. Acad Pediatr. 2009 Sep-Oct;9(5):322-9.

33 Ogden CL, Carroll MD, Lawman HG, Fryar CD, Kruszon-Moran D, Kit BK, et al. Trends in obesity prevalence among children and adolescents in the United States, 1988-1994 through 2013-2014. JAMA. 2016 Jun; 315(21):2292-9.

34 Lo JC, Chandra M, Sinaiko A, Daniels SR, Prineas RJ, Maring B, et al. Severe obesity in children: prevalence, persistence and relation to hypertension. Int J Pediatr Endocrinol. 2014 Mar;2014(1):3.

35 Kharofa RY, Klein JA, Khoury P, Siegel RM. Severe Obesity Decreasing in Children in Cincinnati, Ohio. Clin Pediatr (Phila). 2017 Jul;56(8):752-8.

36 Day SE, Konty KJ, Leventer-Roberts M, Nonas C, Harris TG. Severe obesity among children in New York City public elementary and middle schools, school years 2006-07 through 2010-11. Prev Chronic Dis. 2014 Jul; 11:E118.

37 Robbins JM, Mallya G, Polansky M, Schwarz DF. Prevalence, disparities, and trends in obesity and severe obesity among students in the Philadelphia, Pennsylvania, school district, 2006-2010. Prev Chronic Dis. 2012; 9:E145.

38 Ells LJ, Hancock C, Copley VR, Mead E, Dinsdale H, Kinra S, et al. Prevalence of severe childhood obesity in England: 2006-2013. Arch Dis Child. 2015 Jul;100(7):631-6.

39 Keane E, Kearney PM, Perry IJ, Kelleher CC, Harrington JM. Trends and prevalence of overweight and obesity in primary school aged children in the Republic of Ireland from 2002-2012: a systematic review. BMC Public Health. 2014 Oct;14(1):974.

40 Mellbin T, Vuille JC. Weight gain in infancy and physical development between 7 and $101 / 2$ years of age. Br J Prev Soc Med. 1976 Dec;30(4):233-8.

41 De Spiegelaere M, Dramaix M, Hennart P. The influence of socioeconomic status on the incidence and evolution of obesity during early adolescence. Int J Obes Relat Metab Disord. 1998 Mar;22(3):268-74.

42 Wijnhoven T, van Raaij J, Breda J. WHO European Childhood Obesity Surveillance Initiative: implementation of round 1 (2007/2008) and round 2 (2009/2010) [cited 2018 Dec 14]. Copenhagen: WHO Regional Office for Europe; 2014. Available from: http://www.euro.who.int/_data/assets/pdf_file/0004/258781/COSI-reportround-1-and-2_final-for-web.pdf.

43 Wijnhoven T, Branca F. WHO European Childhood Obesity Surveillance Initiative. Protocol, version January 2008. Copenhagen: World Health Organization Regional Office for Europe; 2008.

44 WHO European Childhood Obesity Surveillance Initiative. Protocol, version October 2012. Copenhagen: World Health Organization Regional Office for Europe; 2012.

45 WHO European Childhood Obesity Surveillance Initiative. Overweight and obesity among 6-9-year-old children. Report of the third round of data collection 2012-2013 [cited 2018 Dec 14]. Copenhagen: WHO Regional Office for Europe; 2018. Available from: http://www.euro.who.int/en/health-topics/diseaseprevention/nutrition/activities/who-european-childhood-obesity-surveillance-initiative-cosi/cosi-publications/who-european-childhood-obesity-surveillance-initiative-overweight-and-obesity-among-69-year-oldchildren.-report-of-the-third-round-of-data-collection-20122013-2018.

46 Council for International Organizations of Medical Sciences, World Health Organization. International ethical guidelines for biomedical research involving human subjects [cited 2018 Dec 14]. Geneva: Council for International Organizations of Medical Sciences; 2002. Available from: https://cioms.ch/shop/product/international-ethical-guidelines-for-biomedical-research-involving-human-subjects-2/.

47 Wijnhoven TM, van Raaij JM, Spinelli A, Rito AI, Hovengen R, Kunesova M, et al. WHO European Childhood Obesity Surveillance Initiative 2008: weight, height and body mass index in 6-9-year-old children. Pediatr Obes. 2013 Apr;8(2):79-97.

48 Wijnhoven TM, van Raaij JM, Spinelli A, Starc G, Hassapidou M, Spiroski I, et al. WHO European Childhood Obesity Surveillance Initiative: body mass index and level of overweight among 6-9-year-old children from school year 2007/2008 to school year 2009/2010. BMC Public Health. 2014 Aug;14(1):806.

49 World Health Organization. WHO AnthroPlus for personal computers manual: software for assessing growth of the world's children and adolescents [cited 2018 Dec 14]. Geneva: World Health Organization; 2009. Available from: https://www.who.int/growthref/tools/en/.

50 Kuczmarski RJ, Ogden CL, Guo SS, Grummer-Strawn LM, Flegal KM, Mei Z, et al. 2000 CDC Growth Charts for the United States: methods and development. Vital Health Stat 11. 2002 May;11(246):1-190.

51 Eurostat. Population on 1 January by age, sex and NUTS 2 region [cited 2018 Dec 14]. Available from: http:// ec.europa.eu/eurostat/data/database.

52 Cattaneo A, Monasta L, Stamatakis E, Lioret S, Castetbon K, Frenken F, et al. Overweight and obesity in infants and pre-school children in the European Union: a review of existing data. Obes Rev. 2010 May;11(5):389-98. 
Spinelli et al.: Childhood Severe Obesity in Europe

53 Lien N, Henriksen HB, Nymoen LL, Wind M, Klepp KI. Availability of data assessing the prevalence and trends of overweight and obesity among European adolescents. Public Health Nutr. 2010 Oct;13 10A:1680-7.

54 Berghöfer A, Pischon T, Reinhold T, Apovian CM, Sharma AM, Willich SN. Obesity prevalence from a European perspective: a systematic review. BMC Public Health. 2008 Jun;8(1):200.

55 Lobstein T, Frelut ML. Prevalence of overweight among children in Europe. Obes Rev. 2003 Nov;4(4):195200.

56 Rossi CE, de Assis Guedes de Vasconcelos F. Birth weight and obesity in children and adolescents: a systematic review. Rev Bras Epidemiol. 2010;13:1-13.

57 Organisation for Economic Co-Operation and Development. Health at a glance: Europe 2012 [cited 2018 Dec 14]. Paris: 2012. Available from: https://www.oecd-ilibrary.org/social-issues-migration-health/health-at-aglance-europe-2012_9789264183896-en.

58 Börnhorst C, Wijnhoven TM, Kunešová M, Yngve A, Rito AI, Lissner L, et al. WHO European Childhood Obesity Surveillance Initiative: associations between sleep duration, screen time and food consumption frequencies. BMC Public Health. 2015 Apr;15(1):442.

59 Hense S, Pohlabeln H, De Henauw S, Eiben G, Molnar D, Moreno LA, et al. Sleep duration and overweight in European children: is the association modified by geographic region? Sleep. 2011 Jul;34(7):885-90.

60 Brug J, van Stralen MM, Te Velde SJ, Chinapaw MJ, De Bourdeaudhuij I, Lien N, et al. Differences in weight status and energy-balance related behaviors among schoolchildren across Europe: the ENERGY-project. PLoS One. 2012;7(4):e34742.

61 Popkin BM, Gordon-Larsen P. The nutrition transition: worldwide obesity dynamics and their determinants. Int J Obes Relat Metab Disord. 2004 Nov;28(S3 Suppl 3):S2-9.

62 World Health Organization. Ending childhood obesity [cited 2018 Dec 14]. Available from: https://apps.who. int/iris/bitstream/handle/10665/274792/WHO-NMH-PND-ECHO-18.1-eng.pdf?ua=1.

63 Langeheine M, Pohlabeln H, Lauria F, Veidebaum T, Tornaritis M, Molnar D, et al. Attrition in the European Child Cohort IDEFICS/I.Family: exploring associations between attrition and body mass index. Front Pediatr. 2018 Aug;6:212.

64 Taveras EM, Hohman KH, Price SN, Rifas-Shiman SL, Mitchell K, Gortmaker SL, et al. Correlates of participation in a pediatric primary care-based obesity prevention intervention. Obesity (Silver Spring). 2011 Feb;19(2): 449-52.

65 Mead E, Brown T, Rees K, Azevedo LB, Whittaker V, Jones D, et al. Diet, physical activity and behavioural interventions for the treatment of overweight or obese children from the age of 6 to 11 years. Cochrane Database Syst Rev. 2017 Jun;6:CD012651.

66 Kelly AS, Barlow SE, Rao G, Inge TH, Hayman LL, Steinberger J, et al.; American Heart Association Atherosclerosis, Hypertension, and Obesity in the Young Committee of the Council on Cardiovascular Disease in the Young, Council on Nutrition, Physical Activity and Metabolism, and Council on Clinical Cardiology. Severe obesity in children and adolescents: identification, associated health risks, and treatment approaches: a scientific statement from the American Heart Association. Circulation. 2013 Oct;128(15):1689-712. 